\title{
Indonesian Children Acquisition On Single Word Utterance Stage: A Case Study
}

\author{
Bambang Yulianto \\ Dept. of Indonesian Language and Literature \\ Universitas Negeri Surabaya \\ Surabaya, Indonesia \\ bambangyulianto@unesa.ac.id
}

\begin{abstract}
This The study is aimed to explain the language sound acquisition of Indonesian utterances of a child aged $1 ; 0-1 ; 6$, including (1) the characteristics of the language sounds (consonants and vowels) and (2) its distribution. The study is based on the qualitative research approach. Viewed from the light of language acquisition, this study employs a diary study as the data collection method. In this method, one subject, named Iza (S1), were observed for six months. She is in the stage of single-word utterance of her language development. The results of the study shows that up to age 1;6, S1 produced 15 consonants and 6 primary vowels, with the acquisition order $[\mathrm{m}, \mathrm{p}, ?, \mathrm{t}, \mathrm{h}, \mathrm{n}$, $b, d, \mathbf{y}, \check{c}, y, \hat{j}, w, k, g]$ for the consonants and $[a, i, u, e, o$,$] for$ vowels. All of these consonants and vowels have the same distribution as Indonesian standard utterance, so that it is universal.
\end{abstract}

\section{Keywords - acquisition, consonant, vowel, distinctive feature}

\section{INTRODUCTION}

The phonological study of children generally focuses on the phonological development [1], particularly in relation to the child's ability to articulate speech sounds at certain stages and phonological processes. In the early stages of development, for example, there is often a certain deviation of sounds. This is a result of the inability of articulation to cooperate when receiving instructions to do so [2].

The development is apparent through gradual stages, which begin to appear to the child as he processes a single word speech in a very simple phonological form toward a relatively more perfect multiword speech. The ability develops through the effort to produce sounds like adult speech and combine them into a more complex phonological structure [3].

Cherry [4] reveals that language acquisition has a gradual beginning, arising from motoric, social, and cognitive achievements. Garcia [5] also states that the child's language acquisition can be said to have characteristics of continuity, possessing a series of unity, moving from a simple word utterances to a more complicated word combinations. Therefore, Chomsky [6] states that the theory of language acquisition should show how the child's language moves from So to Ss.

The language acquisition is largely determined by the intricate interactions between the biological, cognitive, and social maturity aspects [4]; [7]; [8]; [9], and Campbell [10] suggested that a language is built from the beginning by every child by utilizing various innate abilities in his interactions with the physical and social world experiences. Therefore, it is not surprising that most modern approaches to language acquisition focus on one aspect of the acquisition process. Some of them are very concerned about the structural features of the development of linguistic systems; the other approach is on the relationship of speech to the child's cognitive development; while others are paying great attention to the social use of the first language.

Based on this reason, this study focuses on how the language sound (consonants dan vowels) order is acquired in children's Indonesian language and how it is distributed.

\section{METHOD}

The study used a qualitative approach with a longitudinal diary study. In this case one subject (S1) is used to be observed within six months when $\mathrm{S} 1$ is aged from 1;0 to $1 ; 6$. The collecting data is included in the single word utterance stage [11] which is divided into 26 periods ( 1 period is 1 week / 7 days). The subject name is Iza Indriana (Iza, pseudo name). The data were collected by the researcher and assisted by some children as comrades playing the subject.

To get the data from the child's language development was not easy. Sometimes for a long time we did not listen to the child's talks so we have to take a long time to get a word. For that reason, the researchers used elicitation techniques by involving other children to engage in the conversation as well as participant observation techniques with assisted by recording techniques. In addition, we know that the child's utterances are generally imperfect, containing deviation, especially phonological deviations, and sometimes also meaningless. To understand it, we need the context of the conversation. To that end, researchers used field notes and nonparticipant observations to record the speeches and its context.

\section{RESEACH RESULT}

Concerning the focus (1), the results showed that up to age 1,6 S1 have resulted 15 consonants in the order of acquisition $[\mathrm{m}, \mathrm{p}, ?, \mathrm{t}, \mathrm{h}, \mathrm{n}, \mathrm{b}, \mathrm{d}, \mathrm{y}, \breve{\mathrm{c}}, \mathrm{y}, \hat{\mathrm{j}}, \mathrm{w}, \mathrm{k}, \mathrm{g}]$ and 6 main vowels $[\mathrm{a}, \mathrm{i}$, $\mathrm{u}, \mathrm{e}, \mathrm{o}, \mathrm{]}$. Meanwhile, the allophones of the vowels, i.e [I, U, $\varepsilon$, and ] are also acquired. Judging from its distinctive features, the consonant's acquisition order is consonant + anterior, - 
higher, -back, -continuant, -del-rel, -voice, -lateral and they acquired earlier than the contrast pair's consonant. In the vowels, it was found that the -high, +low, +round, -tense were acquired earlier than the contrast pair's vowels.

Of the 15 consonants generated by $\mathrm{S} 1$, there are 11 consonants that can take the initial position, 11 medial consonants, and 6 final position. Whereas, in the Indonesian standard utterance (ISU) of 15 consonants, there are 14 consonant which can be in initial position, 15 medial position, and 8 final position. Based on that, it can be concluded several things. First, the consonant /p/ and $/ \mathrm{k} /$ cannot be produced by $\mathrm{S} 1$ at the final position. Second, consonants $/ ? /, / \mathrm{h} /, / \mathrm{y} /$, and $/ \mathrm{k} /$ have not been able to be produced by $\mathrm{S} 1$ in medial position. Third, consonants $/ \mathrm{h} /, / \mathrm{h} /$, and $/ \mathrm{g} /$ have not been able to be generated by $\mathrm{S} 1$ in initial position. Fourth, all dental consonants that have been acquired by $\mathrm{S} 1$, i.e. $/ \mathrm{t} / \mathrm{d} / \mathrm{d} /$, and /n/. Therefore, it can be concluded that $\mathrm{S} 1$ have a complete distribution as the distribution of the consonants in the ISU. For consonants /d/ which is not produced by $\mathrm{S} 1$ in final position in reality this position in ISU also does not exist. Fifth, in addition to $/ \mathrm{p} /$, as disclosed in the first conclusion above, all labial consonants that have been produced by $\mathrm{S} 1$ have the same distribution as the consonant distribution in the ISU. Sixth, all palatal consonants that have been derived by $\mathrm{S} 1$ have the same distribution with the consonant distribution in the ISU. Seventh, all the velar and glottal consonants that $\mathrm{S} 1$ has produced have a far less complete distribution compared to the consonant distribution in the ISU.

Meanwhile, of the 6 main vowels produced by S1, there are 5 vowels that have a complete distribution and 1 vowel that does not have a complete distribution. The incomplete vowel distribution is / / because this vowel is not present in the final position. In fact, the words containing vowels / / in the final position are not many.

\section{DISCUSSION}

\section{A. Consonant Acquisition}

Do the consonants acquired by $\mathrm{S} 1$ can be acquired in the same order by another child? Detailed data on consonant acquiring order in Echa [12] unfortunately is not shown, so the comparison cannot be done completely. However, in the exposure it was acquired an information that at the age of $1 ; 0$ Echa acquire consonant $/ \mathrm{p} /$ and $/ \mathrm{m} /$; at the age of $1 ; 1$ she gets the consonant $/ \mathrm{n} /$; at the age of $1 ; 1(3)$ she acquires consonant $/ \mathrm{t} /, / \mathrm{d} /$, and $/ \mathrm{b} /$; and at the age of $1 ; 5$ she gets an additional consonant of $/ \mathrm{s} /$ and $/ \mathrm{y} /$.

In the study of Mara [13], it was not acquired the description of the order of consonant acquisition in a continuous time. In her study the data were taken in two observation periods, the first observation period occurred when the age of Mara reached $1: 1(22)$ to $1 ; 3(7)$ and the second observation period occurred when she reached $1 ; 7(13)$ to $1 ; 9(22)$. In this case it can be seen that the distance time between each observation periods was about four months, i.e. between $1 ; 3(8)$ to $1 ; 7(12)$.

In the first observation of Mara the following results are acquired: up to age $1 ; 1(28)$ Mara has been producing the consonants $/ \mathrm{p} /, / \mathrm{h} /, / \mathrm{n} /, / \mathrm{d} /$, and $/ \mathrm{m} / ;$ until the age of $1 ; 2(5)$ Mara acquires additional consonant $/ \mathrm{t} /, / ? /, / \mathrm{b} /, / \mathrm{k} /$; and up to the age of 1;3(7) Mara acquired two additional consonants, /č/ and $/ \mathrm{y} /$.

Based on the description above it can be seen that the first consonant acquired by $\mathrm{S} 1$ is a bilabial $/ \mathrm{m} /$ and $/ \mathrm{p} /$. This also happened to Echa. At the age of 1;0 she just produced the consonants $/ \mathrm{p} /$ and $/ \mathrm{m} /$ [12]; [14]. The dental consonant $/ \mathrm{t} /$ in $\mathrm{S} 1$ is acquired at the age $1 ; 1(10)$. The consonants produced by Echa are also acquired at nearly the same age, i.e. 1:1(3). Previously, at the age of $1 ; 1$, Echa had produced dental-nasal /n/. Furthermore, Echa produced dental and other bilabials, i.e. $/ \mathrm{d} / \mathrm{and} / \mathrm{b} /$. Thus, until the age of $1 ; 1(3)$, Echa just produced bilabial and dental consonants.

Meanwhile, before dental / $\mathrm{t} /$ yield, S1 has been shown to produce glottal /?/ at the age 1;0(20). Thus, until the age $1 ; 1(10) \mathrm{S} 1$ has produced three consonant groups, namely bilabial, dental, and glottal. The consonant acquisition of S1 is the same as Mara. At the age of 1;1(28) Mara also acquired three consonant groups. However, the glottal produced by Mara was $/ \mathrm{h} /$. This consonant produced by $\mathrm{S} 1$ at the fourth place in the age of $1 ; 2(2)$, i.e. after the consonant $/ t /$.

Nasal-velar/y/ on Mara appeared at the age of 1;3(7). In the S1 language development, the consonant appears at almost the same age, i.e. 1;3 (19). On the other hand, Echa the consonant appeared only at the age of 1;5. If bilabial, dental, and velar consonants are compared, it can be stated that bilabial consonants are acquired first, and then dental (Dardjowidjojo grouped them into the alveolar), and the last was velar [12]. Such order of the consonant acquisition is also shown in [15] and Oller et. al. [16]. Thus, the order shows a universality.

Dardjowidjojo [12] also concluded that stop consonant is acquired before fricative. In S1 all ISU's stop consonant has been mastered, while the fricative consonant was acquired $/ \mathrm{h} /$. Fricative $/ \mathrm{f} /, / \mathrm{s} /$, and $/ \mathrm{z} /$ have not been able to be produced by $\mathrm{S} 1$. The consonant until the age of 1;5 has not appeared on Echa, except the consonant $/ \mathrm{s} /$. That was only in the final position. While, Mara until the age 1;3(7) the three fricative consonants are also not yet able to be produced. The order of acquiring such consonants is also shown by Baldwin [15]. Thus, the acquisition of the stop consonant preceding the fricative is universal [17].

The acquisition of nasal consonants begun with nasalbilabial, nasal-dental, and nasal-velar are also seen in the S1, Echa, and Mara data. In this case of the nasal $/ \mathrm{m} /$ consonant is acquired before $/ \mathrm{n} /$ and $/ \mathrm{n} /$ acquired before $/ \mathrm{h} / . \mathrm{S} 1$ acquired $/ \mathrm{m} /$ at the age $1 ; 0(7), / \mathrm{n} /$ at the age $1 ; 2(15)$, and $/ \mathrm{y} /$ at the age $1 ; 3(19)$. While, Echa got the consonant $/ \mathrm{m} /$ at the age $1 ; 0, / \mathrm{n} /$ at the age $1 ; 1 ;$ and $/ \mathrm{y} /$ at the age $1 ; 5$. And Mara acquired $/ \mathrm{m} /$ at the age $1 ; 1(28), / \mathrm{n} /$ at the age $1 ; 1(28) ;$ and $/ \mathrm{y} /$ at the age $1 ; 2(7)$. In this case Mara acquired $/ \mathrm{m} /$ and $/ \mathrm{n} /$ at the same time, as what Baldwin did [15]. Unfortunately, there is no data on Mara before that age. Nevertheless, at least it can be concluded that the nasal-bilabial is acquired earlier than the nasal-velar is universal [12].

In addition, based on its distinctive features, Echa's consonants that acquired in the age 1;5 can be expressed as 
follows. The +anterior was acquired earlier than -anterior consonant. Consonant $/ \mathrm{y} /$ was the only consonant-anterior. The consonant was acquired only when Echa reaches 1;5, while other +anterior consonants have been produced before, i.e starting at age $1 ; 0$ via bilabial $/ \mathrm{m} /$ and $/ \mathrm{p} /$. It was also revealed that a) -high consonants were acquired earlier than +high consonants; b) -back consonant is acquired earlier than +back consonant; c)-continuant consonants are acquired earlier than +continuant consonants; d) -del-rel consonants are acquired earlier than +del-rel consonants; e) -voice consonants are acquired earlier than +voice consonants; and f) -lateral consonants are acquired earlier than + lateral consonants. The similar order occurred also in S1 language development.

Meanwhile, Mara's data showed that a) +anterior was acquired earlier than -anterior; b) -high was also acquired earlier than +high, c) -back was acquired earlier than +back; d) -continuant acquired earlier than +continuant; e) -del-rel was acquired earlier than +del-rel; f) -lateral was acquired earlier than +lateral; and g) -voice was acquired earlier than +voice consonant.

Based on the explanation above, there are a universality of the consonant order based on the distinctive feature, although they are varied (which occurs in Mara). The Universality of consonant acquisition order are generally (a) +anterior is acquired earlier than -anterior; (b) -high is acquired earlier than +high; (c) -back is acquired earlier than +back; (d) -continuant is earlier than +continuant, (e) -del-rel is acquired earlier than +del-rel, (f) -voice isacquired earlier than +voice; and (g) lateral is acquired earlier than +lateral + consonant.

The above statement is consistent with some of Jakobson's predictions about the order of language sounds, that -voice consonants acquired preceded +voice consonant and -back preceded +back consonant (Macken \& Ferguson 1981: 112) [17]. Cole [18] who examined a child with articulation disorder also revealed the same, that-voice consonants are easier to be produced by children with articulation disorders than +voice.

\section{B. Vowel Acquisition}

In single word utterance stage, S1 has acquired all ISU's single vowels, i.e. [a, i, u, e, o, ]. The acquisition of all ISU's single vowels also occurred in Echa until she reached the age $2 ; 0$ [12]. While, until the age of 1;9 (29) Mara has also produced all ISU's single vowels [13]. Meanwhile, the acquisition of diphthongs until the age 1;6 has not occurred in $\mathrm{S} 1$ and Echa. Mara was up to the end of data collection has not been seen producing diphthong.

Is the acquisition of the vowel following a universal order? To see the universality of the order of acquisition of the vowels, it can be noted from Dardjowidjojo's [19] statement that Echa does begin with vowel /a/ and vowel /i/ and /u/, but at the time meaningful words are formed, these three vowels appeared along with other vowels, such as $/ \varepsilon / / / \mathrm{I} /$, and $/ /$. In another description it is disclosed that the vowel $/ \mathrm{a} /$ is acquired at $1 ; 0$ and the vowel $/ \mathrm{i} /$ is acquired at $1 ; 1(3)$. While, the vowels /u/,/o/, and /e/ appeared sporadically.

How about Mara? In the first week of the first observation, i.e. when she was in the age $1 ; 1(22)-1 ; 1(28)$, Mara has produced vowels $/ \mathrm{a} /, \mathrm{i} /$, and $/ \mathrm{u} / \mathrm{at}$ once. The acquisition of these three vowels did not increase until the end of the first observation period, i.e. when Mara was 1;3(7). Unfortunately, the data was not taken before that time, so it is unclear which of the three vowels was acquired earlier. During the observation period both vowels /e/, /o/, and / / were found in Mara. While, in S1 the consonant /a/ is the earliest, followed by /i/. The mastery only on two vowels that lasted a bit longer (about two months). The vowel $/ \mathrm{u} / \mathrm{is}$ acquired after that, followed by /E/ (allophon /e/), /o/, and the last / /.

Although among all the single vowels, Dardjowidjojo expresses his doubt about the order, at least it is revealed that the vowel /a/ is acquired earliest and then $/ \mathrm{i} /$ and $/ \mathrm{u} /$. These three orders are also seen in S1's language development. On the other hand, in Mara's language development it is not clear what the order is. Based on that, it can be stated that the acquisition of vowels order from $/ \mathrm{a} /, \mathrm{i} / \mathrm{/}$, to $/ \mathrm{u} /$ is universal. Of the three vowels there is a tendency of the order of acquisitions as follows: /a/ - /i/ - /u/.

This is in line with Jakobson's remarks [20] and de Villers $\&$ de Villers [14], that /a/, /i/, /u/ are the first vowel phoneme to appear in the child's language development. It is further revealed that all of three vowels are the basic vowels that exist in almost all languages. Why is it so? The vowel /a/ as a low vowel contrasts with the vowel $/ \mathrm{i} /$ and $/ \mathrm{u} /$ as the high vowel. From other point of view, $/ \mathrm{i} /$ and $/ \mathrm{u} /$ are opposite in terms of pitch. The front position of the tongue and the flatness of the lips in producing the vowel /i/ cause the occurrence of a small cavity between the tongue and lips, resulting in a high-pitched vowel. In the contrary, because of the rounded shape of the lips and the tongue moves back when it produces the sound $/ \mathrm{u} /$, and there is a narrowed crack in the lips and the large cavity between the lips and tongue, resulting in a low-pitched vowel.

Jakobson's statement above is also explained by Clark \& Clark [21]. In this case it is also stated that the child's first vowel is /a/. The first contrast to the vowel produced with the lowered tongue position is the vowel produced with the position of the tongue rising without friction, /i/. The vowels produced by the raising of the front tongue are further contrasted with the vowels produced by the raising of the back tongue, $/ \mathrm{u} /$. These three vowels systems are called minimal vowel systems. Furthermore, the addition of other vowels lies in the light of the contrast.

This study seems relevant to Jakobson's universality theory above. After $/ \mathrm{a} /, / \mathrm{i} /$, and $/ \mathrm{u} /$, the acquired vowel is $/ \mathrm{e} /$. This vowel is located between $/ \mathrm{a} /$ and $/ \mathrm{i} /$. Furthermore, the vowel $/ \mathrm{o} /$. This vowel is located between $/ \mathrm{a} /$ and $/ \mathrm{u} /$ and contrasts the position with /e/. The last vowel acquired is / /, which lies between /e/ and /o/.

Based on the above description it can be seen that although it does not apply to all children, they generally appear to get sounds in similar order. This is also expressed by Carrell [22]. Furthermore, Carrell stated that vowel was acquired earlier than consonant. This is influenced by the strong acoustic energy required to produce the sounds. Syllabic sounds required a weaker energies than non-syllable sounds. As a result, in non-syllabic sounds, many children show a difficulty to produce them. The fact is also seen in S1. As has been 
pointed out that vowels up to age 1;6 have been mastered well, otherwise not all consonants are able to master it perfectly.

\section{Consonant and Vowel Distribution}

There was not a complete data of Echa's consonant distribution, whereas in Mara it was only visible until the age $1 ; 3(7)$. Up to age $1 ; 3(26), \mathrm{S} 1$ acquired ten consonants. Mara at the end of the first observation also acquired ten consonants. The ten consonants acquired by both of them are the same. Of the 10 consonants acquired, there are 16 positions from the three distributions for S1 (initial, medial, and final), while in Mara only 15 positions. Although Dardjowidjojo [12] did not fully disclose the consonant distribution acquired by Echa, it is stated that the consonant $/ \mathrm{s} /, / \mathrm{h} /$, and $/ \mathrm{y} /$ in the final position was acquired before another position [12]. It also happened to $\mathrm{S} 1$. Thus, the acquisition of $/ \mathrm{s} /, / \mathrm{h} /$, and $/ \mathrm{y} /$ consonants as the first acquired consonant in the final position is universal.

Unfortunately, the data on the vowel distribution in Mara and Echa up to a single word utterance stage was not acquired so that it cannot be compared with S1.

\section{CONCLUSION}

Based on the above description, it shows that the acquisition of the consonants and vowels in S1 is generally universal. In addition, it is also revealed that in the child's language acquisition, there are always variations, as what Wells [2] stated. The S1's acquisition of-voice precedes +voice, + anterior precedes -anterior, -back precedes +back, stop precedes fricative, nasal-bilabial precedes nasal-velar were also occurred in Mara, Echa, and even in English mother tongue children, such as Amahl [23]

Based on the findings, the order of language sound acquisition and distribution should be considered by teachers, especially in the school for disability in preparing the learning materials, especially those aspect involving the introduction of lexicon. In addition, it is recommended that they have to use the theory of distinctive features in improving the students' speech because its use will facilitate and accelerate the diagnosis of students' language disorder, so that therapy can be done properly and quickly too.

\section{REFERENCES}

[1] L. Menn, Theories of Phonological Development in Harris Winitz (Ed.), Native Language and Foreign Language Acquisition. New York: The New York Academy of Sciences, 1981.

[2] G. Wells, Variation in Child Language" in Paul Fletcher \& Michael Garman (Eds.), Language Acquisition: Studies in First Language Development. Cambridge: Cambridge University Press, 1981.

[3] D. Ingram, "Phonological Development: Production, in Paul Fletcher \& Michael Garman (Eds.), Language Acquisition: Studies in First Language Development, Second Edition," Cambridge: Cambridge University Press, 1986.

[4] L. J. Cherry, A Sociocognitive Approach to Language Development and Its Implications for Education", in Olga K. Garnica \& Martha L. King (Eds), Language, Children, and Society. New York: Pergamon Press, 1979.

[5] E. E. Garcia, Early Childhood Bilingualism. Albuquerqu: University of New Mexico Press, 1983.
[6] N. Chomsky, On Cognitive Structures and Their Development", in M. Piattelli Palmarini (Ed.), The Debate between Jean Piaget and Noam Chomsky. London: Routledge and Kegan Paul, 1980.

[7] S. Cairns, H, The Acquisition of Language. Cambridge: Cambridge University Press, 1986.

[8] W. Klein, Second Language Acquisition. Cambridge: Cambridge University Press, 1990.

[9] D. I. Slobin, The Acquisition of Rusian as a Native language” in Frank Smith \& George A. Miller (Eds.), The Genesis of Language: A Psycholinguistic Approach. Cambridge: The MIT Press, 1978.

[10] R. N. Campbell, Cognitive Development and Child Language”, in Paul Fletcher \& Michael Garman (Eds.), Language Acquisition: Studies in First Language Development. Cambridge: Cambridge University Press, 1981.

[11] D. Ingram, First language Acquisition: Method, Description, and Explanation. Cambridge: Cambridge University Press, 1992.

[12] S. Dardjowidjojo, Echa: Kisah Pemerolehan Bahasa Anak Indonesia. Jakarta: Grasindo, 2000.

[13] P. Raja, "Language Development on Holophrastic and Telegraphic Stage," Universitas Negeri Surabaya, 1998.

[14] P. A. de Villers and J. G. de Villers, Early Language. Cambridge: Harvard University Press, 1982.

[15] Alfred L. Baldwin, Theories of Child Development. New York: John Wiley \& Sons, Inc, 1979.

[16] R. E. Stark, Prespeech Segmental Feature Development" in Paul Fletcher \& Michael Garman (Eds.), Language Acquisition: Studies in First Language Development, Second Edition. Cambridge: Cambridge University Press, 1986.

[17] M. A. Macken and C. A. Ferguson, Phonological Universals in Language Acquisition", in Harris Winitz (Ed.), Native Language and Foreign Language Acquisition. New York: The New York Academy of Sciences, 1981.

[18] R. A. Cole, Perception of Fluent Speech by Children and Adult", in Harris Winitz (Ed.), Native Language and Foreign Language Acquisition. New York: The New York Academy of Sciences, 1981.

[19] S. Dardjowidjojo, Echa: Perkembangan Bahasa Anak Indonesia (Dua Belas Bulan yang Pertama) in PELLBA 9. Yogyakarta, 1996.

[20] S. A. Schane, Generative Phonology. New York: Prentice-Hall, Inc, 1973.

[21] H. H. Clark and E. Clark, Psychology and Language: An Introduction to Psycholinguistics. New York: Harcourt Brace Jovanovich, Inc, 1977.

[22] J. A. Carrell, Disorders of Articulation", in Cynthia M. Shewan (Ed.), Speech and Language Disorders: Selected Readings. New York: Harper \& Row, Publisher, 1987.

[23] N. V. Smith, The Acquisition of Phonology: A Case Study. Cambridge: Cambridge University Press, 1973. 